\title{
LETTER
}

\section{Is the growth of marine copepods limited by food quantity or quality?}

\author{
Thomas R. Anderson $\left(1,{ }^{1 *}\right.$ Dag 0 . Hessen $\left(\mathbb{0},{ }^{2}\right.$ Daniel J. Mayor $\mathbb{( 1 )}^{3}$ \\ ${ }^{1}$ Marine Systems Modelling, National Oceanography Centre, European Way, Southampton, UK; ${ }^{2}$ Centre of \\ Biogeochemistry in the Anthropocene and Department of Bioscience, University of Oslo, Oslo, Norway; ${ }^{3}$ Ocean \\ Biogeosciences, National Oceanography Centre, European Way, Southampton, UK
}

\section{Scientific Significance Statement}

Marine copepods are ubiquitous and play important roles in sustaining fish stocks, nutrient cycling, and carbon sequestration in deep waters. Our ability to represent these tiny animals in ocean biogeochemical models is hindered by an incomplete understanding of how the quantity and quality of food influence their growth. Using a state-of-the-art model that includes an explicit representation of metabolism, and which has carbon and nitrogen as currencies, we demonstrate that copepod growth is limited by the quantity of organic matter consumed when feeding on typical marine phytoplankton. Our work highlights the benefit of incorporating realistic physiology into plankton models and paves the way for improved predictions of the role of copepods in models of fish production and global biogeochemical cycles.

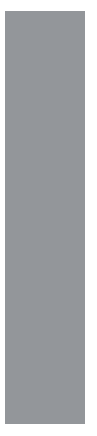

\begin{abstract}
Understanding what limits the growth of marine copepods is important for modeling food web dynamics and biogeochemical cycles in the ocean. We use a state-of-the-art stoichiometric model that explicitly represents metabolic physiology to examine the roles of food quantity vs. quality in limiting the growth of these animals. The model predicts that the crossover from C- to N-limitation occurs at food C : N 7.3-11.5 mol C mol N${ }^{-1}$, depending on food quantity. Thus, despite significant losses of $\mathrm{N}$ in metabolism, copepods should be limited by $\mathrm{C}$ when consuming food at Redfield $\mathrm{C}: \mathrm{N}$ (6.625). We nevertheless suggest that copepods do not seek C-rich diets per se. Rather, results indicate limitation by food quantity as growth increases with organic matter intake, regardless of its elemental composition. Our work highlights the benefit of developing mechanistic representations of zooplankton metabolism in order to increase confidence in the predictions of biogeochemical models.
\end{abstract}

Copepods are integral to marine food webs and biogeochemical cycling in the ocean via grazing on phytoplankton, transfer of carbon (C) to higher trophic levels including fish, nutrient recycling, and export of $\mathrm{C}$ and nitrogen (N) to deep waters (Steinberg and Landry 2017). Understanding what limits copepod growth is therefore essential for developing

*Correspondence: tra@noc.ac.uk

Associate editor: Alison Derry

Author Contribution Statement: TRA undertook model construction and generation of results. TRA, DOH, and DJM all contributed to interpretation of model results and writing of the manuscript, and approved the submitted version.

Data Availability Statement: Model code (in R) to reproduce results is provided in Supporting Information Section S4. Previously published data (Kiørboe 1989) were used for model verification. These data were digitized from the original publication, which is available as a free download at https:// www.int-res.com/articles/meps/55/m055p229.pdf. We tabulate the digitized data in Supporting Information Section S5.

Additional Supporting Information may be found in the online version of this article.

This is an open access article under the terms of the Creative Commons Attribution License, which permits use, distribution and reproduction in any medium, provided the original work is properly cited. 
and parameterizing equations that describe trophic transfer and cycling of $\mathrm{C}$ and $\mathrm{N}$ in marine ecosystems. There are nevertheless "worrying inconsistencies" in the way these equations are formulated and implemented in ocean biogeochemical models, highlighting uncertainty in our understanding of the underlying processes (Anderson et al. 2013).

Laboratory studies have indicated that the growth of marine copepods increases with food quality in terms of $\mathrm{N}$ content, that is, limitation by $\mathrm{N}$ (Libourel-Houde and Roman 1987; Cowles et al. 1988; Kiørboe 1989). In contrast, other studies have suggested that growth is limited by food quantity, based on observed relationships between fecundity and food concentration (Huntley and Boyd 1984; Hirst and Bunker 2003). The importance of food quantity vs. quality in limiting the growth of copepods can also be assessed using ecological stoichiometry. This theoretical framework involves comparing elemental ratios in consumers and their prey and, taking into account growth efficiencies, calculating a threshold elemental ratio (TER) that defines the crossover from limitation by one element to the other. In the case of $\mathrm{C}$ and $\mathrm{N}$, limitation is by $\mathrm{C}$ when food $\mathrm{C}: \mathrm{N}<\mathrm{TER}$, and by $\mathrm{N}$ when food $\mathrm{C}: \mathrm{N}>\mathrm{TER}$. The food of heterotrophic organisms contains organic $\mathrm{C}$ by definition such that $\mathrm{C}$ is commonly thought of as a measure of food quantity (Hessen 2008). Limitation by $\mathrm{C}$ and food quantity may therefore be considered equivalent, implying that growth increases as a function of intake until saturation, irrespective of its macromolecular and elemental composition.

Using simple empirical measures of growth efficiency, previously calculated TERs were much greater than the Redfield $\mathrm{C}: \mathrm{N}$ ratio of $6.625 \mathrm{~mol} \mathrm{C}$ mol N $\mathrm{N}^{-1}$ that characterizes marine phytoplankton (Finkel et al. 2010; Frigstad et al. 2014) suggesting that marine copepods are strongly limited by $\mathrm{C}$ (Anderson and Hessen 1995). This result was, however, inconclusive because the modeled gross growth efficiencies (GGEs) for $\mathrm{N}$ were considerably higher than values measured in

Table 1. Model parameters

\begin{tabular}{lll}
\hline Parameter & \multicolumn{1}{c}{ Description } & \multicolumn{1}{c}{ Value } \\
\hline$\beta_{V}$ & Absorption efficiency: protein & 0.62 \\
$\beta_{H}$ & $\begin{array}{l}\text { Absorption efficiency: } \\
\text { carbohydrate }\end{array}$ & 0.53 \\
$\theta_{Z}$ & Zooplankton C: $\mathrm{N}$ ratio & $5.9 \mathrm{~mol} \mathrm{C} \mathrm{mol} \mathrm{N}^{-1}$ \\
$\theta_{V}$ & Protein C:N ratio & $3.7 \mathrm{~mol} \mathrm{C} \mathrm{mol} \mathrm{N}^{-1}$ \\
$\tau$ & Biomass turnover & $0.06 \mathrm{~d}^{-1}$ \\
$\xi$ & Basal metabolism & $0.038 \mathrm{~d}^{-1}$ \\
$\eta$ & Specific dynamic action & 0.072 \\
$\gamma_{N}$ & Max net synthesis efficiency: & 0.9 \\
& $\mathrm{~N}$ & 0 \\
$\phi$ & Metabolic penalty & \\
\hline
\end{tabular}

laboratory experiments (Checkley Jr 1980; Kiørboe 1989). State-of-the-art ecological stoichiometry models now represent metabolism, and hence growth efficiencies, with explicit metabolic terms for biomass turnover, basal metabolism, and specific dynamic action (SDA) (Anderson et al. 2017, 2020). Here, we use one such model (Anderson et al. 2020) to investigate the role of food quantity vs. quality in limiting the growth of marine copepods. Predicted growth efficiencies are first validated against laboratory data (Kiørboe 1989) to ensure that the values assigned to metabolic parameters are appropriate. Physiologically derived TERs are then calculated which indicate that, when feeding on a typical diet at the Redfield ratio, copepods are limited by food quantity. This implies that copepods may have evolved to avoid $\mathrm{N}$ limitation and maximize growth based on the lowest common denominator, bulk food availability.

\section{Model description}

In this section, we provide an outline of the model structure and assumptions, a brief account of parameter values (Table 1) and the main equation for the TER. A full list of equations, along with detailed justification of the parameter values, is provided in Supporting Information Section S1. The model achieved a good fit to data without the need for tuning of parameter values; the sensitivity of predicted TERs to these values is shown in Supporting Information Section S2.

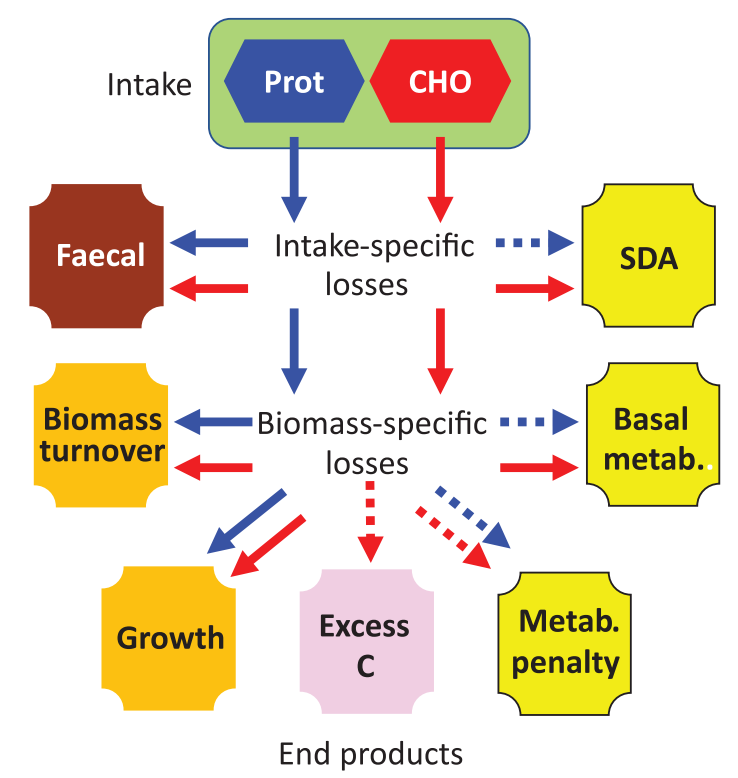

Fig. 1. Flow diagram of model showing use of ingested protein and carbohydrate ( $\mathrm{CHO}$ ) leading to fecal matter (brown), biomass synthesis (orange; requires $C$ and $N$ ), energetic costs (yellow; require $C$ ), and excess $C$ (pink). Dotted lines are conditional in that carbohydrate is prioritized for generation of energy, the metabolic penalty is optional, and excess $C$ only arises when $\mathrm{N}$ is limiting. 

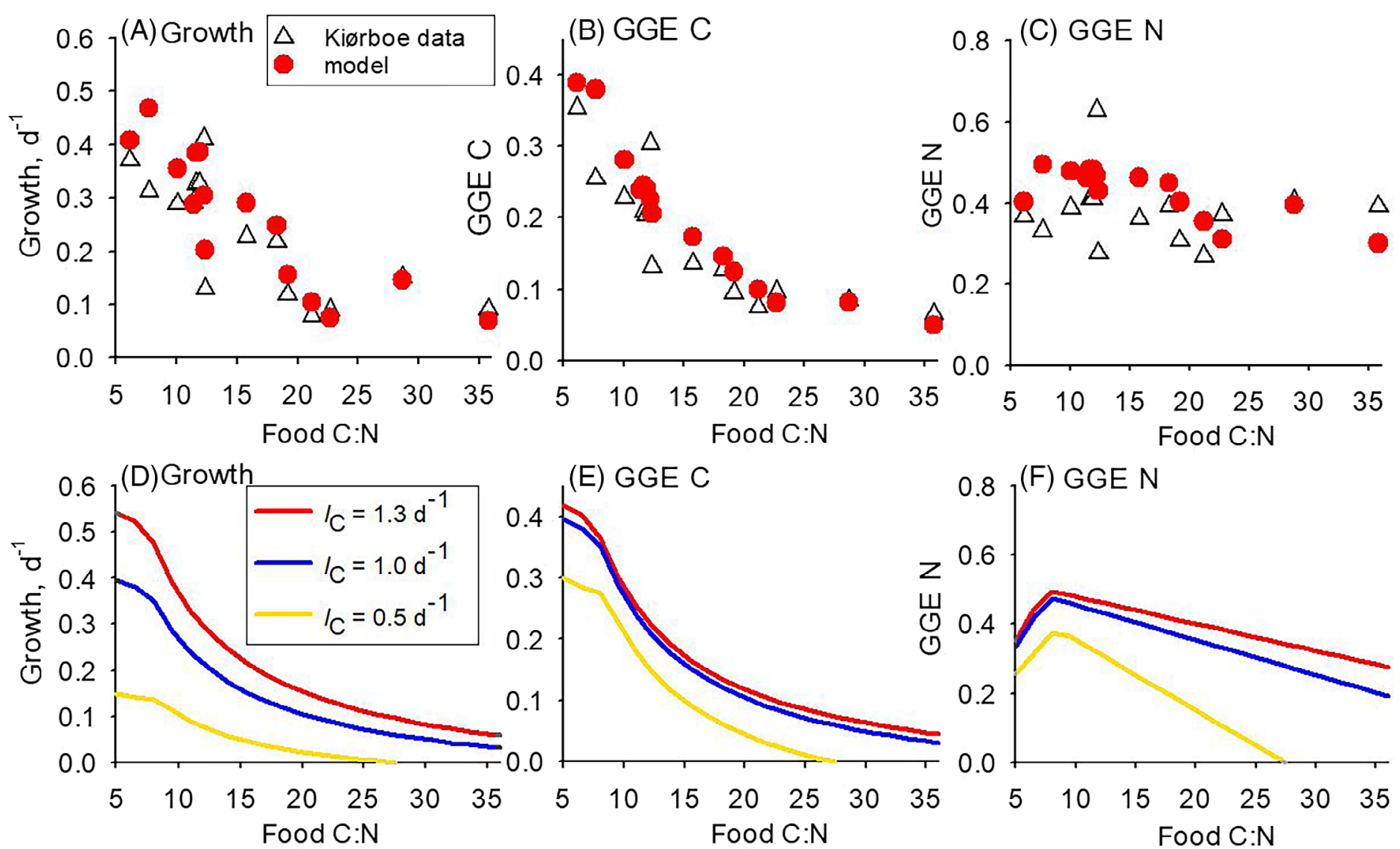

(E) GGE C
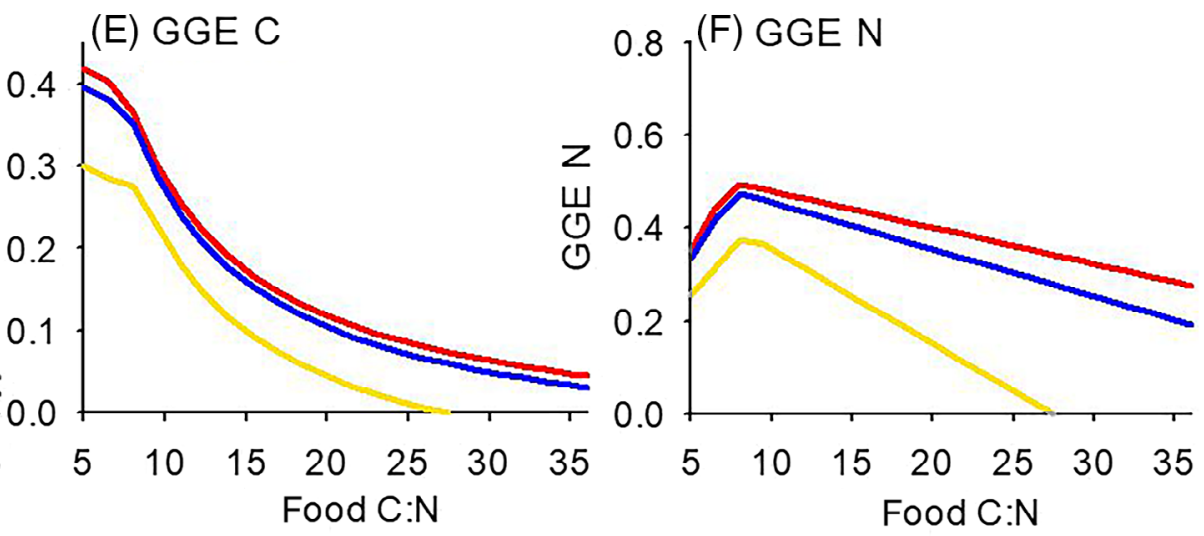

Fig. 2. Comparison of model predictions (red) with data (open triangles) for Acartia tonsa (Kiørboe 1989), using measured $C$ intake for each data point: (A) growth, (B) GGE for C, (C) GGE for N. Corresponding smoothed relationships are shown in panels $(\mathbf{D})-(\mathbf{F})$, for intake $I_{C}=1.3($ average for the data), $1.0,0.5 \mathrm{~mol} \mathrm{C} \mathrm{mol} \mathrm{C}^{-1} \mathrm{~d}^{-1}$.

Animals process food as macromolecules and so, although our focus is on $\mathrm{C}$ and $\mathrm{N}$, model currencies are protein and carbohydrate (denoted $\mathrm{V}$ and $\mathrm{H}$, respectively). The former has a fixed $\mathrm{C}: \mathrm{N}$ ratio (molar) in the model, $\theta_{V}=3.7$. A constant $\mathrm{C}: \mathrm{N}$ ratio is also used for consumer biomass, $\theta_{Z}=5.9$, thereby assuming maintenance of homeostasis, as in most stoichiometric models. Fixed fractions of consumed protein and carbohydrate are assumed to be absorbed $\left(\beta_{V}=0.62, \beta_{H}=0.53\right.$, respectively), with the remainder lost as fecal material. Absorbed substrates are used for growth and metabolism, where metabolism is explicitly represented using mechanistic terms for biomass turnover, other basal metabolism and SDA (Fig. 1). Biomass turnover (parameter $\tau=0.06 \mathrm{~d}^{-1}$ ) is proportional to biomass and requires both $\mathrm{C}$ and $\mathrm{N}$ in ratio $\theta_{Z}$. Other basal metabolism $\left(\xi=0.038 \mathrm{~d}^{-1}\right)$ is an energetic (C) cost that represents cellular processes such as the generation of adenosine triphosphate (ATP) and the maintenance of macromolecular and ionic gradients (Karr et al. 2012). SDA represents the energetic costs of searching for and capturing prey, ingestion, absorption, and assimilation and is specified as fixed fraction of $C$ intake $(\eta=0.072)$. Copepods do not store $C$ in the model and so $C$ that is in stoichiometric excess (Fig. 1), that is, surplus to requirements, must be released in order to maintain homeostasis of biomass. We assume that this $\mathrm{C}$ is respired (Anderson et al. 2020); our results and conclusions are unaffected by this assumption.

Carbohydrate is assumed to be used preferentially to meet the energetic costs of metabolism thereby sparing protein (and $\mathrm{N}$ ) for growth, while the use of protein $\mathrm{N}$ for biomass synthesis is assumed not to be $100 \%$ efficient (parameter $\left.\gamma_{N}=0.9\right)$. A novel feature of the model is that it includes a metabolic penalty (parameter $\phi$ ) that is incurred when protein is used for energy, representing the energetic costs of dealing with the production and excretion of toxic nitrogenous waste (Anderson et al. 2020). We set $\phi=0$ (no penalty) as default, but will also show results for $\phi=0.25,0.5$.

The calculation of the TER, $\theta_{\mathrm{CN}}^{*}$ (the superscript "«" denotes that all energetic costs are met using carbohydrate), depends on predicted minimum rations for protein and carbohydrate, $I_{V m}$ and $I_{H m}^{*}\left(m o l ~ C ~ m o l ~ C^{-1} \mathrm{~d}^{-1}\right)$ below which the animal is in deficit, $\mathrm{C}$ intake remaining for growth (total intake less the minimum rations), $I_{\mathrm{CG}}$, and the predicted optimal $\mathrm{C}: \mathrm{N}$ ratio 
for growth, $\theta_{\mathrm{CNG}}^{*}$. The equation for $\theta_{\mathrm{CN}}^{*}$ is (see Supporting Information Section S1 for a full derivation):

$$
\theta_{\mathrm{CN}}^{*}=\theta_{V}\left(\frac{I_{H m}^{*}+I_{\mathrm{CG}}\left(1-\theta_{V} / \theta_{\mathrm{CNG}}^{*}\right)}{I_{V m}+I_{\mathrm{CG}} \theta_{V} / \theta_{\mathrm{CNG}}^{*}}+1\right)
$$

The TER is uninfluenced by the metabolic penalty because energetic costs are met solely using carbohydrate when nutrition is optimal. R code for calculating the TER is supplied in Supporting Information Section S4.

\section{Results}

Comparison with data

For validation purposes, we first compare predictions of the model with data for growth (egg production) and the associated GGEs for $\mathrm{C}$ and N, measured for the copepod Acartia tonsa feeding on cultures of the diatom Thalassiosira weissflogii with a range of food $\mathrm{C}$ : $\mathrm{N}$ ratios between 6 and 36 (Kiørboe 1989). Model predictions show good agreement, noting that predictions are made using the measured $\mathrm{C}$ intake for each individual data point (Fig. 2A-C). Growth and GGE C decline with increasing food $\mathrm{C}: \mathrm{N}$ ratio while, as noted by Kiørboe (1989), GGE for $\mathrm{N}$ is more or less constant at $\sim 0.38$. The smoothed relationships are shown in Fig. 2D-F, for intake $I_{\mathrm{C}}=1.3$ (corresponding to average intake in the Kiørboe data), 1.0 and $0.5 \mathrm{~mol} \mathrm{C} \mathrm{mol} \mathrm{C} \mathrm{C}^{-1} \mathrm{~d}^{-1}$, where the corresponding TERs are 7.4, 7.6, and 8.3, respectively. Growth and GGEs for $\mathrm{C}$ and $\mathrm{N}$ decline when food $\mathrm{C}: \mathrm{N}$ ratio $>$ TER as $\mathrm{N}$ becomes progressively more limiting in the diet. Predicted growth and GGE $\mathrm{C}$ increase with decreasing food $\mathrm{C}: \mathrm{N}$ when food $\mathrm{C}: \mathrm{N}<\mathrm{TER}$, that is, when $\mathrm{C}$ is limiting, because the absorption efficiency for protein is greater than that of carbohydrate (0.62 vs. 0.53). In contrast, GGE $\mathrm{N}$ decreases as excess $\mathrm{N}$ in protein is released in order to maintain homeostasis.

\section{Threshold elemental ratio}

Predicted TER decreases with increasing $\mathrm{C}$ intake and is greater than the Redfield ratio of 6.625 throughout its range (Fig. 3), indicating limitation by $\mathrm{C}$ for food with Redfield $\mathrm{C}: \mathrm{N}$. The maximum TER of 11.5 represents the $\mathrm{C}: \mathrm{N}$ of metabolism in the absence of growth and occurs at the minimum ration, $I_{\mathrm{C}}=0.21 \mathrm{~mol} \mathrm{C} \mathrm{mol} \mathrm{C}^{-1} \mathrm{~d}^{-1}$, below which animals are have insufficient food to meet metabolic requirements. The predicted $\mathrm{C}: \mathrm{N}$ of growth (in isolation from basal metabolism, i.e., $\tau=\xi=0$ ) is 7.0 (Supporting Information Eq. S6), lower than that of metabolism because growth as a process requires relatively less energy. Predicted TER therefore decreases with increasing $I_{\mathrm{C}}$, reaching a value of 7.3 at $I_{\mathrm{C}}=2.0 \mathrm{~mol} \mathrm{C} \mathrm{mol} \mathrm{C} \mathrm{C}^{-1}$. All but one of the Kiørboe (1989) data points are encapsulated within $\mathrm{N}$-limited phase space (food $\mathrm{C}: \mathrm{N}>\mathrm{TER}$ ), noting that the animals were supplied a replete ration and so had relatively high intake. Predicted

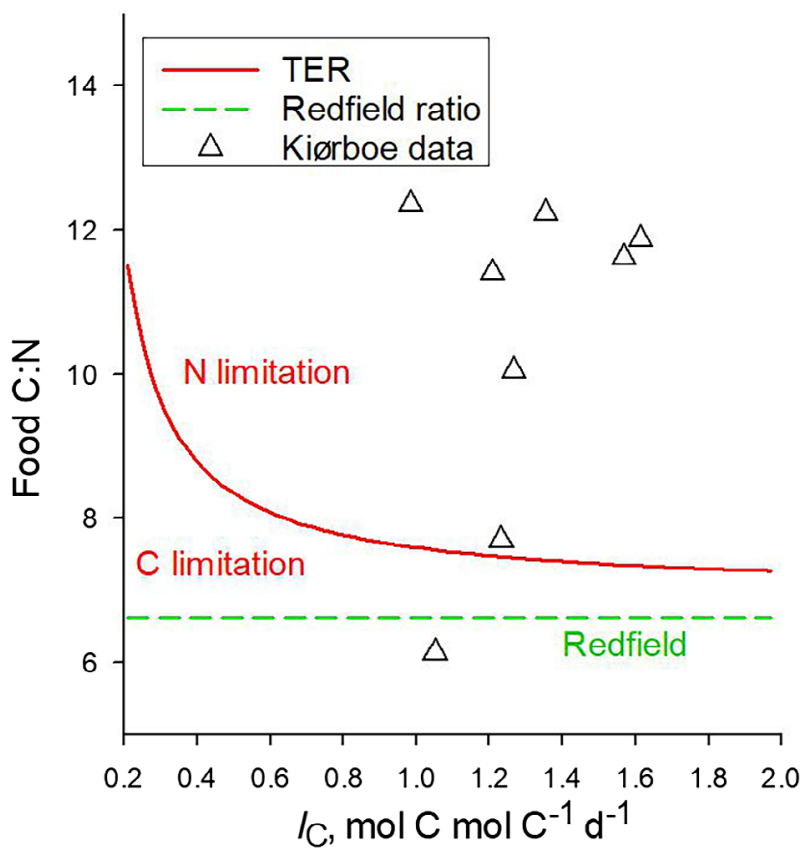

Fig. 3. Predicted TER (red line), showing a maximum of 11.5 at the minimum $C$ ration $\left(I_{C}=0.21 \mathrm{~mol} \mathrm{C} \mathrm{mol} \mathrm{C}{ }^{-1} \mathrm{~d}^{-1}\right)$, decreasing with increasing intake as metabolic costs become proportionally less. Also shown is the Redfield ratio of 6.625 (green dashed line) and the Kiørboe (1989) data (triangles; excluding data for food $\mathrm{C}: \mathrm{N}>14$ ).

TERs are relatively insensitive to changing parameter values (see Supporting Information Section S2).

The relationship between food $\mathrm{C}: \mathrm{N}$ and predicted growth, intake, and TER is shown in Fig. 4 , for $I_{\mathrm{C}}=0.5,1.0 \mathrm{~mol} \mathrm{C} \mathrm{mol}$ $\mathrm{C}^{-1} \mathrm{~d}^{-1}$. For illustrative purposes, the analysis is simplified by

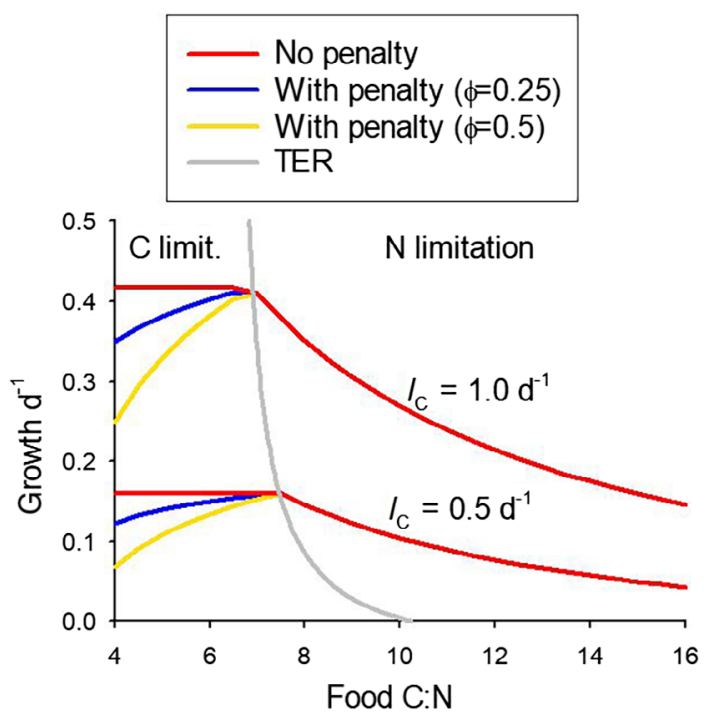

Fig. 4. Predicted growth vs. food $C: N$ for intake $I_{C}=0.5,1.0 \mathrm{~mol} C$ mol $\mathrm{C}^{-1} \mathrm{~d}^{-1}$, without (red) and with metabolic penalty $(\phi=025$ blue; $\phi=0.5$ gold). Lines overlap for food $C: N \geq$ TER. Parameters as in Table 1 except $\beta_{H}=0.62$. 
assuming that the AEs for protein and carbohydrate are the same $\left(\beta_{V}=\beta_{H}=0.62\right.$; see Supporting Information Section S3 for results when using standard parameter settings of $\left.\beta_{V}=0.62, \beta_{H}=0.53\right)$. Growth is limited by $\mathrm{N}$ when food $\mathrm{C}: \mathrm{N}>$ TER and, as expected, declines with increasing food $\mathrm{C}: \mathrm{N}$ as $\mathrm{N}$ becomes progressively scarce in the diet. In contrast, it is flat, that is, unchanging with food $\mathrm{C}: \mathrm{N}$ ratio, to the left of the TER (red lines, Fig. 3) meaning that all food types within C-limited phase space are of equal merit for maximizing copepod growth. In other words, copepods are limited by the quantity of food intake, irrespective of its macromolecular and elemental composition. If absorption efficiencies are unequal, then prey items that are absorbed most efficiently will be favored. The situation changes when the metabolic penalty, which is an energetic cost associated with dealing with toxicity arising from using protein as a source of energy, is introduced into the analysis $(\phi=0.25,0.5)$. Predicted growth rate is then highest at the TER, falling away both to the right where $\mathrm{N}$ is limiting, and to the left as the diet becomes progressively protein-rich (Fig. 4). The TER is uninfluenced by the penalty because energetic costs are met solely using carbohydrate when nutrition is optimal.

\section{Discussion}

Copepods require $\mathrm{C}$ and $\mathrm{N}$ in food for growth and metabolism. The TER, which in theory represents optimal food $\mathrm{C}: \mathrm{N}$ in nutrition, thus depends on zooplankton body composition and physiology. Using state-of-the-art stoichiometric theory that incorporates explicit terms for metabolism, we predicted TERs for copepods of 7.3-11.5, depending on food quantity. This range is above the canonical Redfield ratio of 6.625 that represents the typical $\mathrm{C}: \mathrm{N}$ of marine phytoplankton and seston more generally (Finkel et al. 2010; Frigstad et al. 2014), although values can sometimes significantly exceed Redfield in natural systems (Daly et al. 1999; Finkel et al. 2010) and in nutrient-limited chemostat cultures (Kiørboe 1989). The conventional interpretation of TER $>$ food $\mathrm{C}: \mathrm{N}$ in terms of stoichiometric mass balance is that copepods experience limitation by $\mathrm{C}$ in marine systems. This might give the impression that copepods should maximize $\mathrm{C}$ intake with respect to nutrient elements, in which case high $\mathrm{C}: \mathrm{N}$ foods such as detritus could be most favorable. A more plausible interpretation is that growth increases with total organic matter intake, irrespective of its $\mathrm{C}: \mathrm{N}$ ratio. In other words, limitation is by food quantity, consistent with correlative evidence relating growth and food concentration in marine systems (Huntley and Boyd 1984; Hirst and Bunker 2003).

Knowing whether copepods are limited by food quantity or quality is crucial for understanding and predicting their role in marine ecosystems, including trophic transfer to fish and $\mathrm{C}$ and $\mathrm{N}$ cycling and sequestration in the ocean. Ocean warming, along with the associated reduction in nutrient supply to surface waters via increased stratification, will likely increase phytoplankton $\mathrm{C}: \mathrm{N}$ ratio (Tanioka and Matsumoto 2020). This increase may adversely affect copepod growth if limitation is by food quality $(\mathrm{N})$, and conversely may be of little consequence if food quantity is limiting. Understanding these trophic interactions, including the effect of climate warming on the physiology of phytoplankton and zooplankton, is necessary for the accurate parameterization of copepod growth and trophic transfer in ocean biogeochemical models (Anderson et al. 2013, 2017).

The idea that copepods can be limited by dietary $\mathrm{C}$ deficiency is not new. High-latitude species may favor C-rich diets to accumulate storage lipids in order to meet their energetic requirements during diapause and reproduction (Mayor et al. 2009). Using a stoichiometric model with simple empirical GGEs, Anderson and Hessen (1995) calculated TERs > Redfield, as in our study, concluding that copepods should "commonly be limited by C." Their model, however, showed a striking mismatch with experimental data in that predicted GGEs for $\mathrm{N}$ were much higher than the low and relatively constant measured values of only $\sim 0.38$ (Checkley Jr 1980; Kiørboe 1989). Overestimating N GGE strengthens the case for $\mathrm{C}$ limitation, giving rise to predicted TERs that are too high such that even severe restriction of dietary $\mathrm{N}$ does not adversely impact on growth, in contrast to the findings of laboratory studies (Libourel-Houde and Roman 1987; Cowles et al. 1988; Kiørboe 1989). Sparing of protein for growth is well known in animals (Li et al. 2012) and it may seem paradoxical that $\mathrm{N}$ should be used with a low efficiency when it is limiting in the diet.

Previous stoichiometric models which calculate growth efficiencies using simple empirical parameterizations (Anderson and Hessen 1995; Anderson et al. 2013) show considerable mismatch with the data of Kiørboe (1989). The model used herein shows good agreement with this data set, including $\mathrm{N}$ GGE. Confidence in our results is enhanced by the fact that GGE in the model is calculated based on a mechanistic representation of metabolism, where model parameter values are assigned directly from measurements instead of being tuned. The low N GGEs are explained by metabolic losses of $\mathrm{N}$ in biomass turnover; the modeled turnover rate is $0.06 \mathrm{~d}^{-1}$, based on estimates for Calanus spp. (Mayor et al. 2011). This "inefficiency" of $\mathrm{N}$ use in metabolism means that animals are more likely to be N-limited. Our predicted TERs are nevertheless greater than the Redfield ratio, indicating that limitation is by food quantity (C) rather than $\mathrm{N}$ but, unlike the previous assessment by Anderson and Hessen (1995), only by a narrow margin. Given that the TER represents optimal nutrition, it makes sense that copepods have evolved a metabolic machinery where the TER is close to Redfield, narrowly offsetting limitation by $\mathrm{N}$ such that growth is determined by bulk food availability.

Limitation by food $\mathrm{C}$ necessarily entails that $\mathrm{N}$ is in excess according to stoichiometric mass balance. This excess must be excreted or otherwise disposed of in order to avoid the 
accumulation of toxic waste, incurring energetic costs associated with deamination of protein, metabolic transformations and excretion (Bender 2012; Zhang et al. 2020). Our model includes a metabolic penalty that is quantified as an energetic (C) cost proportional to the excess $\mathrm{N}$ (Anderson et al. 2020). Introducing the penalty leads to decreased growth when protein is used as a source of energy, that is, with increasing protein (decreasing food $\mathrm{C}: \mathrm{N}$ ) in the diet for food $\mathrm{C}: \mathrm{N}<\mathrm{TER}$. Predicted growth is then highest at the TER, falling away either side (Fig. 4). This pattern of results represents a stoichiometric "knife-edge" in which growth is adversely affected when nutrient elements are in either deficit or excess. Experimental studies have shown a knife-edge for freshwater invertebrates (Elser et al. 2016) although focusing on potential limitation by phosphorus $(\mathrm{P})$, rather than $\mathrm{N}$. Whereas $\mathrm{C}$ and $\mathrm{N}$ are tightly coupled in macromolecules and metabolism, $\mathrm{P}$ is associated with energy delivery (ATP), membranes (phospholipids), and nucleic acids. Moreover, unlike N, P may be reclaimed and utilized for growth with nearly 100\% efficiency, even when scarce in the diet (Olsen et al. 1986). It is as yet unclear whether marine copepods experience metabolic penalties associated with excess $\mathrm{N}$, and if they do, whether such penalties are of sufficient magnitude to significantly impact on growth and reproduction. Our predicted TERs and associated conclusions regarding limitation of growth by food quantity (for food $\mathrm{C}: \mathrm{N}<\mathrm{TER}$ ) are not altered if penalties come into play, with the exception that growth is then maximized at the TER rather than simply proportional to intake.

Food quality has the potential to override food quantity and limit copepod growth, although just how often this occurs is in reality is not well known. Both observational and theoretical studies have shown the potential for the availability of polyunsaturated fatty acids to limit copepod production, especially when individual plankton types, for example, diatoms dominate the plankton assemblage (Anderson and Pond 2000; Jónasdóttir et al. 2009). Copepods may seek a nutritionally diverse diet in order to minimize this possibility (Kleppel 1993), for example, through trophic upgrading by utilizing microzooplankton that are rich in specific fatty acids, sterols, and amino acids (Stoecker and Capuzzo 1990; Klein Breteler et al. 1999). Limitation by $\mathrm{N}$ is also possible. Kiørboe (1989) concluded that $\mathrm{N}$ was the limiting constituent of the food in his experiments which is consistent with our findings given that the $\mathrm{C}: \mathrm{N}$ ratios of the diatom prey were, with only two exceptions, greater than 10 (Fig. 3).

In conclusion, our stoichiometric model, which is underpinned by a mechanistic representation of metabolism, predicts TERs of 7.3-11.5 indicating that marine copepods commonly avoid limitation by $\mathrm{N}$ in which case they are instead limited by food quantity as growth increases with organic matter intake, regardless of its macromolecular and elemental composition. Our work demonstrates that mechanistic representation of zooplankton metabolism in biogeochemical models can provide new and valuable insights into what limits the growth of consumer organisms and thereby our understanding of the fate of carbon and nutrient elements within ecosystems and the ocean.

\section{Acknowledgment}

TRA and DJM received funding from the Natural Environment Research Council, UK, programmes CLASS (award number NE/R015953/1) and DIAPOD (NE/P006353/1)

\section{References}

Anderson, T. R., and D. O. Hessen. 1995. Carbon or nitrogen limitation in marine copepods? J. Plankton Res. 17: 317-331. doi:10.1093/plankt/17.2.317.

Anderson, T. R., and D. W. Pond. 2000. Stoichiometric theory extended to micronutrients: Comparison of the roles of essential fatty acids, carbon, and nitrogen in the nutrition of marine copepods. Limnol. Oceanogr. 45: 1162-1167. doi:10.4319/lo.2000.45.5.1162.

Anderson, T. R., D. O. Hessen, A. Mitra, D. J. Mayor, and A. Yool. 2013. Sensitivity of secondary production and export flux to choice of trophic transfer formulation in marine ecosystem models. J. Mar. Syst. 125: 41-53. doi:10.1016/j. jmarsys.2012.09.008.

Anderson, T. R., D. O. Hessen, M. Boersma, J. Urabe, and D. J. Mayor. 2017. Will invertebrates require increasingly carbon-rich food in a warming world? Amer. Nat. 190: 725-742. doi:10.1086/694122.

Anderson, T. R., D. Raubenheimer, D. O. Hessen, K. Jensen, W. C. Gentleman, and D. J. Mayor. 2020. Geometric stoichiometry: Unifying concepts of animal nutrition to understand how protein-rich diets can be "too much of a good thing". Front. Ecol. Evol. 8: 196. doi:10.3389/fevo.2020.00196.

Bender, D. A. 2012. The metabolism of "surplus" amino acids. Br. J. Nutr. 10: S113-S121. 10.1017/S0007114512002292.

Checkley, D. M., Jr. 1980. The egg production of a marine planktonic copepod in relation to its food supply: Laboratory studies. Limnol. Oceanogr. 25: 430-446. doi:10.4319/ lo.1980.25.3.0430.

Cowles, T. J., R. J. Olson, and S. W. Chisholm. 1988. Food selection by copepods: Discrimination on the basis of food quality. Mar. Biol. 100: 41-49. doi:10.1007/BF00392953.

Daly, K. L., D. W. R. Wallace, W. O. Smith Jr., A. Skoog, R. Lara, M. Gosselin, E. Falck, and P. L. Yager. 1999. NonRedfield carbon and nitrogen cycling in the Arctic: Effects of ecosystem structure and dynamics. J. Geophys. Res. 104: 3185-3199. doi:10.1029/1998JC900071.

Elser, J. J., M. Kyle, J. Learned, M. L. McCrackin, A. Peace, and L. Steger. 2016. Life on the stoichiometric knife-edge: Effects of high and low food C:P ratio on growth, feeding, and respiration in three Daphnia species. Inland Waters 6: 136-146.

Finkel, Z. V., J. Beardall, K. J. Flynn, A. Quigg, T. A. V. Rees, and J. A. Raven. 2010. Phytoplankton in a changing world: Cell size and elemental stoichiometry. J. Plankton Res. 32: 119-137. doi:10.1093/plankt/fbp098. 
Frigstad, H., T. Andersen, R. G. J. Bellerby, A. Silyakova, and D. O. Hessen. 2014. Variation in the seston C:N ratio of the Arctic Ocean and pan-Arctic shelves. J. Mar. Syst. 129: 214-223. doi:10.1016/j.jmarsys.2013.06.004.

Hessen, D. O. 2008. Efficiency, energy and stoichiometry in pelagic food webs; reciprocal roles of food quality and food quantity. Freshw. Rev. 1: 43-57. doi:10.1608/FRJ-1.1.3.

Hirst, A. G., and A. J. Bunker. 2003. Growth of marine planktonic copepods: Global rates and patterns in relation to chlorophyll $a$, temperature, and body weight. Limnol. Oceanogr. 48: 1988-2010. doi:10.4319/lo.2003.48.5.1988.

Huntley, M., and C. Boyd. 1984. Food-limited growth of marine zooplankton. Amer. Nat. 124: 455-478.

Jónasdóttir, S. H., A. W. Visser, and C. Jespersen. 2009. Assessing the role of food quality in the production and hatching of Temora longicornis eggs. Mar. Ecol. Prog. Ser. 382: 139-150. doi:10.3354/meps07985.

Karr, J. R., and others. 2012. A whole-cell computational model predicts phenotype from genotype. Cell 150: 389-401. doi: 10.1016/j.cell.2012.05.044.

Kiørboe, T. 1989. Phytoplankton growth rate and nitrogen content: Implications for feeding and fecundity in a herbivorous copepod. Mar. Ecol. Prog. Ser. 55: 229-234.

Klein Breteler, W. C. M., N. Schogt, M. Baas, S. Schouten, and G. W. Kraay. 1999. Trophic upgrading of food quality by protozoans enhancing copepod growth: Role of essential lipids. Mar. Biol. 135: 191-198. doi:10.1007/s002270050616.

Kleppel, G. S. 1993. On the diets of calanoid copepods. Mar. Ecol. Prog. Ser. 99: 183-195.

Li, X., Y. Jiang, W. Liu, and X. Ge. 2012. Protein-sparing effect of dietary lipid in practical diets for blunt snout bream (Megalobrama amblycephala) fingerlings: Effects on digestive and metabolic responses. Fish Physiol. Biochem. 38: 529_ 541. . doi:10.1007/s10695-011-9533-9.

Libourel-Houde, S. E., and M. R. Roman. 1987. Effects of food quality on the functional ingestion response of the copepod Acartia tonsa. Mar. Ecol. Prog. Ser. 40: 69-77.
Mayor, D. J., T. R. Anderson, D. W. Pond, and X. Irigoien. 2009. Limitation of egg production in Calanus finmarchicus in the field: A stoichiometric analysis. J. Mar. Syst. 78: 511-517. doi: 10.1016/j.jmarsys.2008.12.020.

Mayor, D. J., K. Cook, B. Thornton, P. Walsham, U. F. M. Witte, A. F. Zuur, and T. R. Anderson. 2011. Absorption efficiencies and basal turnover of $\mathrm{C}, \mathrm{N}$ and fatty acids in a marine Calanoid copepod. Funct. Ecol. 25: 509-518. doi: 10.1111/j.1365-2435.2010.01791.x.

Olsen, Y., A. Jensen, H. Reinertsen, K. Y. Børsheim, M. Heldal, and A. Langeland. 1986. Dependence of the rate of release of phosphorus by zooplankton on the P:C ratio in the food supply, as calculated by a recycling model. Limnol. Oceanogr. 31: 34-44. doi:10.4319/lo.1986.31.1.0034.

Steinberg, D. K., and M. R. Landry. 2017. Zooplankton and the ocean carbon cycle. Ann. Rev. Mar. Sci. 9: 413-444.

Stoecker, D. K., and J. M. Capuzzo. 1990. Predation of protozoa: Its importance to zooplankton. J. Plankton Res. 12: 891-908.

Tanioka, T., and K. Matsumoto. 2020. A meta-analysis on environmental drivers of marine phytoplankton $\mathrm{C}: \mathrm{N}: \mathrm{P}$. Biogeosciences 17: 2939-2954. doi:10.5194/bg-17-29392020.

Zhang, S., J. S. Johnson, N. Qiao, and N. L. Trottier. 2020. Reduced protein diet with near ideal amino acid profile improves energy efficiency and mitigate heat production associated with lactation in sows. J. Anim. Sci. Biotechnol. 11: 4. doi:10.1186/s40104-019-0414-x.

\section{Conflict of Interest}

The authors declare no potential conflicts of interest.
Submitted 24 October 2020 Revised 25 January 2021 Accepted 08 February 2021 